\title{
Retinitis pigmentosa unilateral: reporte de 2 casos
}

\section{Unilateral retinitis pigmentosa: report of two cases}

\author{
Antonio Ramos-Suárez ${ }^{1 *}$, Francisco José Barrero-Sojo ${ }^{1}$, Ana Belén González-Escobar ${ }^{1}$, \\ Saturnino Gismero-Moreno ${ }^{1}$, Mercedes Lorenzo-Soto ${ }^{2}$ y Fernando García-Martín ${ }^{2}$
}

${ }^{1}$ Licenciatura en Medicina; ${ }^{2}$ Doctorado en Medicina. Especialidad en Oftalmología, Departamento de Oftalmología en el Hospital Costa del Sol, Marbella, Málaga, España

\section{Resumen}

La retinitis pigmentosa $(R P)$ constituye la distrofia retiniana hereditaria que presenta una mayor prevalencia. Típicamente la enfermedad es bilateral y simétrica. Los casos de RP unilateral son muy poco frecuentes, y solo existen en la literatura reportes de casos aislados o series con un número reducido de casos. Presentamos 2 casos clínicos de RP unilateral. En el primer caso describimos una mujer de 38 años diagnosticada de RP unilateral en su ojo izquierdo y un periodo de seguimiento de 10 años. En el segundo caso describimos un varón de 64 años con RP unilateral complicada con un edema macular cistoide desde el momento diagnóstico en su ojo derecho y 6 años de seguimiento.

Palabras clave: Retinitis pigmentosa unilateral. Catarata subcapsular posterior. Edema macular quístico. Funduscopia. Electrorretinograma.

\section{Abstract}

Retinitis pigmentosa $(R P)$ is the most prevalent form of hereditary retinal dystrophy. Typically the disease is bilateral and symmetrical. Cases of unilateral RP are very rare and only isolated cases or short series have been reported. We present two cases of unilateral RP. In the first, a 38-year-old woman was diagnosed with unilateral RP in the left eye, and followed up for 10 years. In the second, we describe a 64-year-old male with unilateral RP complicated with cystoid macular edema in the right eye, from the time of diagnosis, followed up for 6 years.

Key words: Unilateral retinitis pigmentosa. Posterior subcapsular cataract. Cystoid macular oedema. Funduscopy. Electroretinography.

Fecha de recepción: 18-04-2016

Fecha de aceptación: 04-07-2016 DOI: 10.1016/j.mexoft.2016.07.002
Disponible en internet: 30-07-2016 Rev Mex Oftalmol. 2018;92(5):260-264 www.rmo.com.mx 


\section{Introducción}

La retinitis pigmentosa (RP) es la distrofia retiniana más frecuente. Constituye un grupo heterogéneo de entidades clínica y genéticamente diversas. Su denominador común es una afectación de los fotorreceptores, de los bastones en etapas iniciales y en estadios más evolucionados también de los conos ${ }^{1-3}$.

La enfermedad puede tener una presentación esporádica o seguir un patrón de herencia autosómico dominante $(A D)$, recesivo o ligado al cromosoma $X$. El patrón de herencia más frecuente es el AD. La forma ligada al cromosoma $X$ es la menos frecuente, aunque la más grave ${ }^{1-5}$.

Se presenta típicamente en la segunda o tercera década de la vida, con una pérdida característicamente bilateral y simétrica de las funciones visuales. Los pacientes suelen comenzar con nictalopía y una constricción concéntrica y progresiva del campo visual ${ }^{1,3}$. La visión central puede alterarse en fases evolucionadas de la enfermedad por aparición de edema macular cistoide (EMC) o catarata subcapsular posterior, entre otras'1.

El hallazgo típico en la funduscopia ${ }^{1,3}$ son las espículas óseas intrarretinianas, que inicialmente aparecen en la retina medioperiférica, aunque pueden estar ausentes en algunos casos de la enfermedad, como en la RP sin pigmento. Otros signos característicos son estenosis arteriolar y palidez cérea del disco óptico.

La forma de presentación unilateral es extremadamente infrecuente, y la mayoría de trabajos hacen referencia a casos clínicos aislados o series de casos con pocos pacientes ${ }^{1-6}$.

Se han realizado estudios en los que esta enfermedad ha sido tratada con vitamina $A$, aunque no existen evidencias de que su uso sea beneficioso $0^{7,8}$.

Presentamos 2 casos clínicos de RP unilateral con varios años de seguimiento.

\section{Caso clínico 1}

Mujer de 38 años de edad, sin antecedentes personales ni familiares de interés, que acudió por primera vez a consulta en el año 2006 por sensación de visión borrosa en su ojo izquierdo (OI) de varios años de evolución.

En la exploración la presión intraocular fue de $16 \mathrm{~mm} \mathrm{Hg}$ en el ojo derecho (OD) y de $18 \mathrm{~mm} \mathrm{Hg}$ en el OI. La máxima agudeza visual corregida (MAVC) fue de unidad en el OD y 0.7 en el Ol. El polo anterior era normal en ambos ojos (AO). La funduscopia del OD resultó normal, pero en el Ol se apreció dispersión pigmentaria en forma de espículas que llegaban hasta las arcadas vasculares respetando la mácula, palidez del disco óptico y estrechamiento arteriolar (Figs. 1 A y B).

Se solicitó un electrorretinograma (ERG), que resultó normal tanto en condiciones escotópicas como fotópicas en el OD. En el OI se apreció una respuesta desestructurada tanto en condiciones escotópicas como fotópicas.

Se realizó un campo visual (CV) que resultó normal en el OD. En el Ol se apreció un escotoma anular absoluto en el que se respetaba un pequeño islote de visión central-inferior (Figs. $1 \mathrm{C}$ y D).

Ante estos hallazgos, y dado el corto periodo de seguimiento, se llegó al diagnóstico de RP presuntamente unilateral.

La paciente fue seguida con revisiones anuales $\sin$ presentar cambios, salvo por el inicio de desarrollo de una catarata subcapsular posterior en el OI. En la visita de 2016 la paciente refiere disminución de agudeza visual en el OI. La MAVC fue de 0.9 en el OD y de 0.4 en su OI. En el polo anterior del OD se apreció una catarata subcapsular posterior incipiente. En el Ol se apreció una catarata subcapsular posterior evolucionada (Figs. $1 \mathrm{E}$ y F). Los hallazgos funduscópicos no presentaron alteraciones con respecto a anteriores visitas. EI ERG y el CV permanecieron estables. Se consensuó con la paciente continuar con actitud expectante y revisiones anuales.

\section{Caso clínico 2}

Varón de 54 años de edad, sin antecedentes personales ni familiares de interés, que acudió por primera vez a consulta en el año 2010 por disminución de la agudeza visual en su OD de 3 días de evolución. El paciente refería peor visión en el OD que en el OI desde hacía al menos 10 años, pero nunca antes consultó a un oftalmólogo.

En la exploración la presión intraocular fue de $9 \mathrm{~mm} \mathrm{Hg}$ en AO. La MAVC fue 0.3 en OD y unidad en el OI. El polo anterior era normal en AO. En la funduscopia del OD se apreciaron cúmulos de pigmento en forma de espículas óseas en la zona ecuatorial de la retina. Además se apreció palidez papilar y estrechamiento arteriolar, junto con una mácula atrófica. La funduscopia del Ol resultó normal (Figs. 2 A y B).

Se realizó tomografía de coherencia óptica (OCT) que mostró un EMC con quistes de discreto tamaño y perfil foveal conservado con atrofia macular en el OD. La OCT del Ol resultó normal (Figs. 2 C y D). 


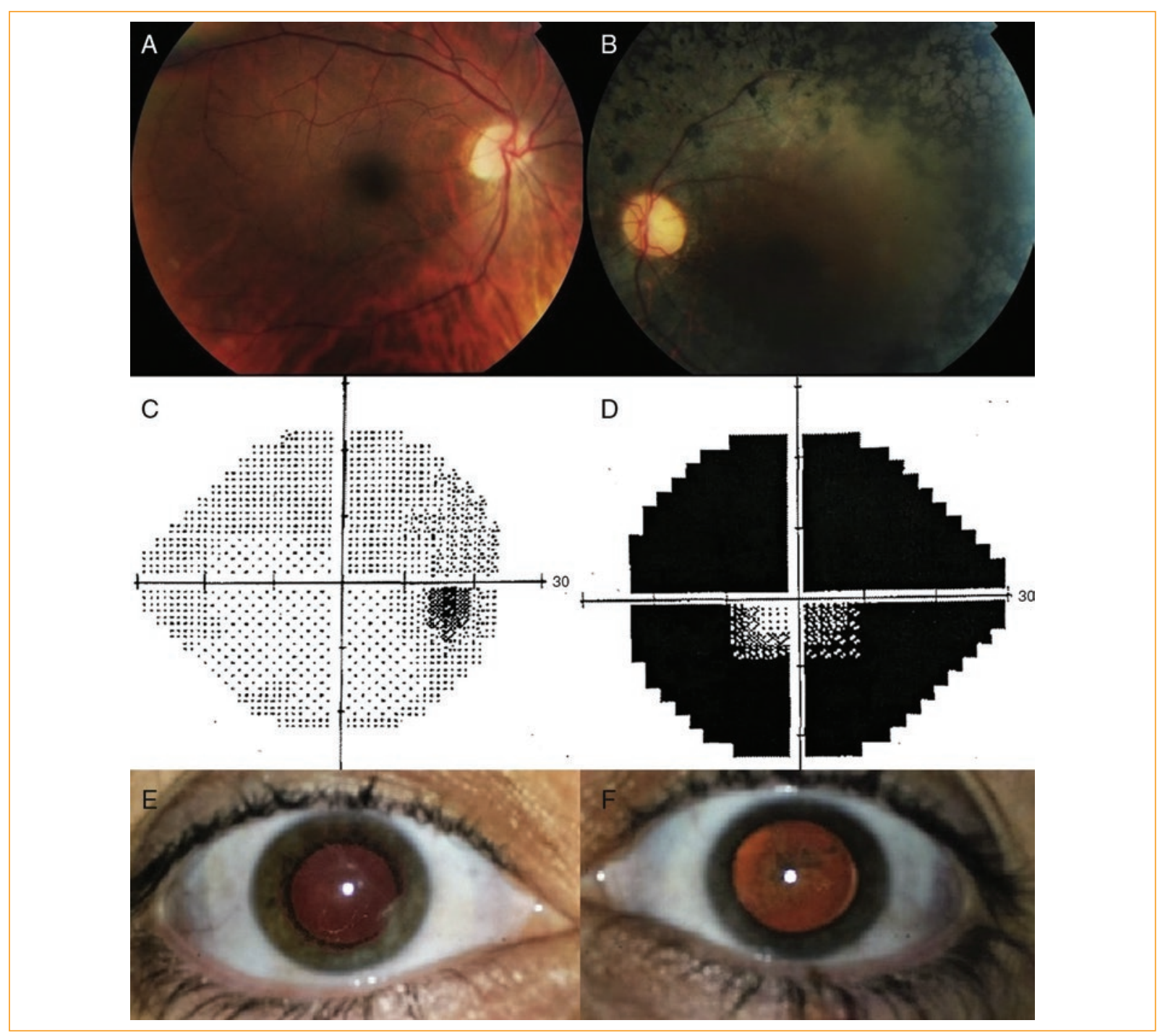

Figura 1. A: La retinografía del OD fue normal. B: En la retinografía del Ol se aprecian multitud de espículas muy confluentes que llegan hasta las arcadas, respetando la mácula, con palidez papilar y estrechamiento arteriolar. C: La campimetría Humphrey (24-2) del OD es normal. D: En la campimetría Humphrey (24-2) del Ol se aprecia un escotoma anular absoluto con respeto de un pequeño islote de visión central-inferior. E: Tras 10 años de seguimiento en el OD se aprecia una catarata subcapsular posterior incipiente. F: Tras 10 años de seguimiento en el Ol se aprecia una catarata subcapsular posterior evolucionada.

Se solicitó un ERG que mostró ausencia de respuesta de bastones y una respuesta de conos con latencia aumentada y amplitud disminuida en el OD. El OI resultó normal tanto en condiciones escotópicas como fotópicas.

El CV del OD mostró un escotoma absoluto, mientras que el Ol fue normal (Figs. 2 E y F).

Ante estos hallazgos, y dado el corto periodo de seguimiento, se llegó al diagnóstico de RP presuntamente unilateral complicada con un EMC.

El paciente rechazó iniciar tratamiento para el EMC, por lo que se optó por una actitud conservadora con revisiones periódicas. Permanece estable tras 6 años de seguimiento.

\section{Discusión}

La RP unilateral constituye una forma de presentación muy poco frecuente de RP. Fue descrita por primera vez en 1865 por Pedraglia9. Los síntomas y hallazgos funduscópicos en el ojo afectado son idénticos a la forma bilateral, sin embargo la edad de presentación suele ser mayor ${ }^{4}$. Los pacientes con RP unilateral pueden desarrollar sus actividades diarias 


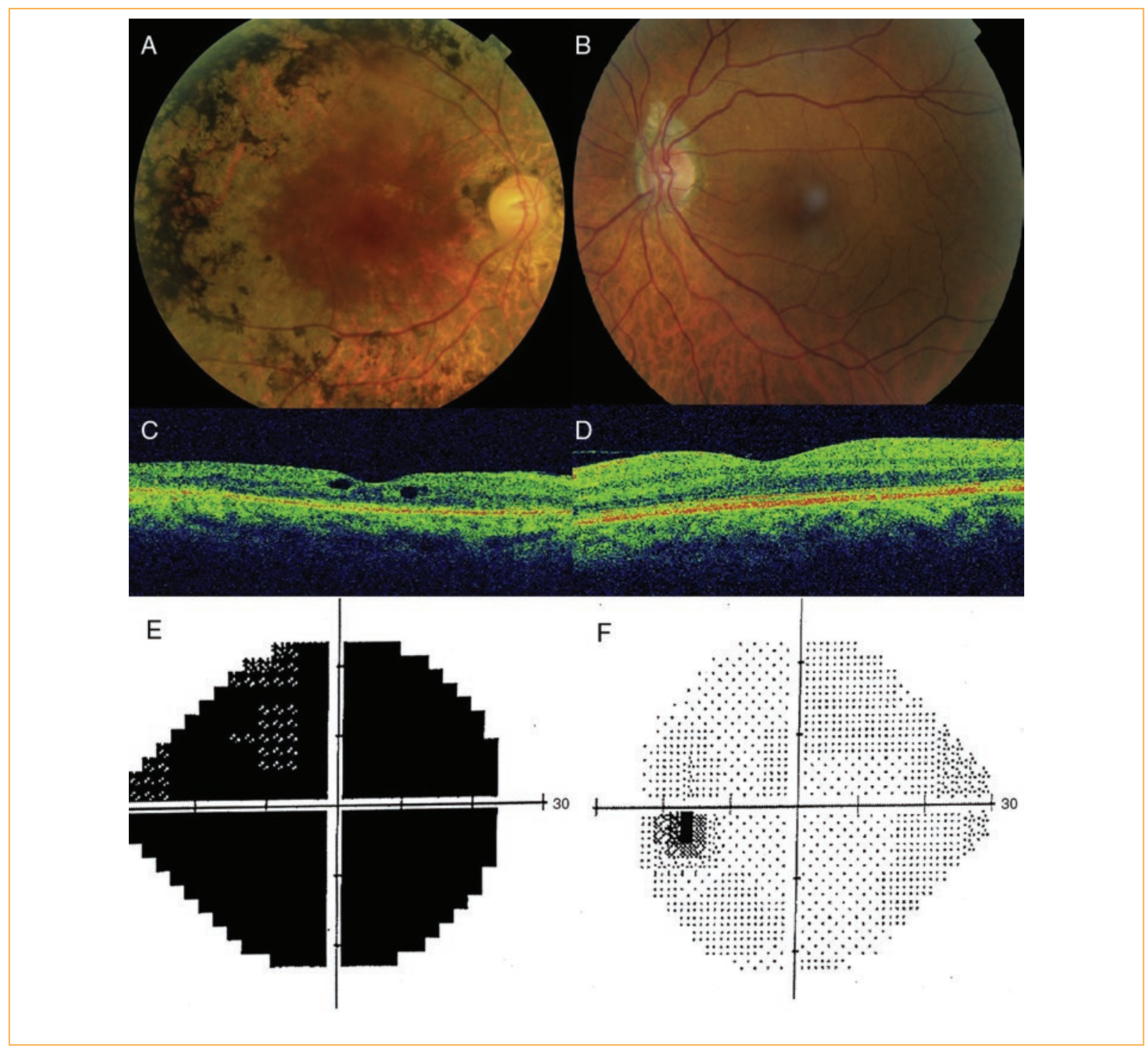

Figura 2. A: En la retinografía de la primera visita del OD se aprecian espículas óseas, palidez papilar y estrechamiento arteriolar junto con una mácula atrófica. B: Retinografía normal en el Ol. C: En la tomografía de coherencia óptica del OD se aprecian pequeños quistes en las capas medias de la retina con perfil foveal conservado y atrofia macular. D: En la tomografía de coherencia óptica del Ol no se aprecian alteraciones. E: La campimetría Humphrey (24-2) del OD muestra un escotoma absoluto. F: La campimetría Humphrey (24-2) del 0l es normal.

prácticamente con normalidad gracias al ojo sano. Este hecho podría justificar una consulta médica más tardía y, por consiguiente, una edad de presentación mayor al diagnóstico que la forma bilateral. En nuestro primer caso la paciente mostró la edad típica de presentación al diagnóstico, si bien no consultó de forma precoz, ya que la afectación en su Ol no le incapacitaba para el desarrollo de las actividades en su vida diaria. Nuestro segundo caso presentó una edad muy avanzada al diagnóstico, pese a haberse iniciado los síntomas en el OD muchos años atrás, ya que la visión del Ol le permitía realizar las actividades de su vida diaria sin incapacidad.

El hecho de que una enfermedad de origen genético se presente solo en un ojo podría explicarse por 2 fenómenos $^{1,2}$ : por un lado podría deberse a un posible mosaicismo genético en el que la mutación afectaría solo a unas células. Por otro lado, la aparición de una mutación somática que solo estaría presente en algunas células podría explicar la presentación unilateral de la enfermedad. Sin embargo, los mecanismos genéticos que aparecen en esta entidad no son conocidos con exactitud. 
Los criterios diagnósticos de RP unilateral fueron propuestos por François et al. ${ }^{10}:$ 1) aparición de hallazgos típicos funcionales y funduscópicos de RP en un ojo; 2) ausencia de síntomas de distrofia tapeto-retiniana en el ojo contralateral con un ERG normal; 3) exclusión de causas infecciosas, inflamatorias y vasculares que explicaran los cambios en el ojo afectado; y 4) periodo de seguimiento suficiente como para descartar la aparición de RP en el ojo contralateral (al menos 5 años). Nuestros 2 casos cumplen los 4 criterios, por lo que podemos considerarlos como de RP unilateral confirmada.

Existen casos en los que la RP unilateral se ha asociado a otros trastornos como heterocromía de iris, síndrome pseudoexfoliativo, foseta papilar, arteritis de la temporal o glaucoma. El hecho de que la RP sea una enfermedad muy poco frecuente hace difícil conocer si estas asociaciones se deben solo al azar o si existe una verdadera asociación entre ellas ${ }^{6}$. Durante nuestro seguimiento, el caso número 1 desarrolló cataratas subcapsulares posteriores en $\mathrm{AO}$, más evolucionada en su $\mathrm{OI}$, pero se consensuó con la paciente una actitud expectante con revisiones periódicas. El caso número 2 presentó un EMC desde el momento diagnóstico. Existen varias opciones terapéuticas para el manejo de esta complicación, como por ejemplo inhibidores de la anhidrasa carbónica tópicos o sistémicos, o inyecciones intravítreas de antiangiogénicos o corticoides ${ }^{1}$, sin embargo nuestro paciente rechazó cualquier forma de tratamiento y decidió continuar con revisiones periódicas.

El diagnóstico diferencial debe incluir ${ }^{1,4}$ :

- Procesos infecciosos: la infección congénita por rubeola o Treponema pallidum puede provocar cambios en la funduscopia que recuerden a una RP. La afectación puede ser uni o bilateral.

- Retinopatía por tóxicos: las fenotiazinas producen típicamente una maculopatía, aunque también pueden producir una afectación en la periferia retiniana similar a la RP. Algo similar puede ocurrir con la cloroquina y la hidroxicloroquina.

- Traumatismos contusos: pueden dar lugar a cambios en el epitelio pigmentario de la retina semejantes a los que aparecen en la RP.

- Procesos inflamatorios: uveítis o enfermedades autoinmunes.

\section{Conclusión}

Pese a que la RP constituye la distrofia retiniana hereditaria más frecuente, su presentación unilateral es extremadamente rara. Para poder llegar al diagnóstico de RP unilateral se precisan cumplir los 4 criterios diagnósticos, precisando por tanto un periodo de seguimiento mínimo de 5 años.

Sus mecanismos patogénicos no son del todo bien conocidos en la actualidad, en parte debido al escaso número de casos recogidos hasta la fecha.

No existen opciones de tratamiento satisfactorias, por lo que el seguimiento y tratamiento de las posibles complicaciones que puedan acontecer en el curso de la enfermedad, como EMC o catarata subcapsular posterior, sería una actitud adecuada.

\section{Responsabilidades éticas}

Protección de personas y animales. Los autores declaran que para esta investigación no se han realizado experimentos en seres humanos ni en animales.

Confidencialidad de los datos. Los autores declaran que han seguido los protocolos de su centro de trabajo sobre la publicación de datos de pacientes.

Derecho a la privacidad y consentimiento informado. Los autores declaran que en este artículo no aparecen datos de pacientes.

\section{Financiamiento}

Los autores no recibieron patrocinio para llevar a cabo este artículo.

\section{Conflicto de intereses}

Los autores declaran no tener ningún conflicto de intereses.

\section{Bibliografía}

1. Weller JM, Michelson G, Juenemann AG. Unilateral retinitispigmentosa: 30 years follow-up. BMJ Case Rep. 2014; 2014, bcr2013202-236.

2. Mukhopadhyay R, Holder GE, Moore AT, et al. Unilateral retinitispigmentosa occurring in an individual with a germline mutationin the RP1 gene. Arch Ophthalmol. 2011;129:954-6.

3. Thakur A, Puri L. Unilateral retinitis pigmentosa. Clin Exp Optom. 2010:93:102-4.

4. Farrell DF. Unilateral retinitis pigmentosa and cone-rod dys-trophy. Clin Ophthalmol. 2009;3:263-70.

5. Daiger S, Sullivan L, Bowne S. Genes and mutations causingretinitis pigmentosa. Clin Genet. 2013;84:132-41.

6. Echevarría-Lucas L, Nievas-Gómez T, Peralta-Reyes F, et al. Reti-nosis pigmentaria unilateral asociada a foseta papilar. Estudiodiagnóstico y terapéutico. Rev Mex Oftalmol. 2014;88:39-47.

7. Berson EL, Rosner B, Sandberg MA, et al. A randomized trial ofvitamin $A$ and vitamin $E$ supplementation for retinitis pigmen-tosa. Arch Ophthalmol. 1993;111:761-72.

8. Jacobson SG, Cideciyan AV. Treatment possibilities for retinitispigmentosa. New Engl J Med. 2010;363:1669-71.

9. Pedraglia C. Klinische beobachtungen retinitis pigmentosa. KlinMbl Augenheilk. 1865;3:114-7.

10. Franc, ois J, Verriest G. Retinopathie pigmentaire unilaterale.Ophthalmologica. 1952;124:65-87. 